\title{
Identifying whale-watching tourist differences to maximize return on investment
}

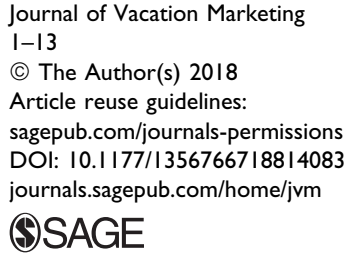

(S)SAGE

\author{
Aaron Tkaczynski \\ University of Queensland, Oceania \\ Sharyn Rundle-Thiele \\ Griffith University, Oceania
}

\begin{abstract}
To maximize return on investment, tourism stakeholders should target tourists who yield the highest dividends. Extending research that focused on understanding environmental concerns at the expense of economic return expected at the destination, this study drew on a range of segmentation bases to ensure a holistic tourist view was gained. A total of 727 whale-watching tourists were segmented, and four valid segments were identified. A fifth targeting criterion (sustainability) was proposed to extend Kotler's (( 1 988) Marketing Management: Analysis, Planning, Implementation, and Control. Englewood Cliffs: Prentice Hall.) targeting criteria. Although all segments were interested in whale watching and conserving the natural environment, the wealthy domestic family segment was the largest and most reachable group. These tourists also had the highest income and they were highly educated, suggesting a focus on this segment will optimize return on investment while conserving the natural environment.
\end{abstract}

\section{Keywords}

Interest, nature, target marketing, whale watching, wildlife tourism

\section{Introduction}

Wildlife tourism encompasses mental, spiritual, and psychological outcomes (Curtin, 2006). It is thought to be an experiential form of nonconsumptive tourism where humans will engage with wildlife where the 'focal organism is not purposefully removed or permanently affected by the engagement' (Duffus and Dearden, 1990: 215). Wildlife animals can be viewed in different locations such as within captive locations such as zoos or aquariums to wild locations such as migratory routes (e.g. oceans) or breeding sites (Reynolds and Braithwaite, 2001).

Whale watching is a popular form of nonconsumptive wildlife tourism that involves tourists getting close to whales and having the opportunity to experience wildlife in its natural habitat (Orams, 2000). Tourists can view whales in their natural environment from marine vessels
(Duffus, 1988), land (Finkler and Higham, 2004), or from swimming with the cetaceans (Valentine et al., 2004). Despite the generic term 'whale watching' being applied, this concept encompasses other cetacean species such as dolphins and porpoises (Parsons et al., 2003b).

Whale watching represents a large economic source of income for some tourism destinations (Ryan et al., 2018; Wilson and Tisdell, 2003). It has provided employment for many whalewatching operators (Wilson and Tisdell, 2003) and generated millions of dollars in revenue for the tourism industry (Lopez and Pearson, 2017;

\footnotetext{
Corresponding author:

Aaron Tkaczynski, School of Business, Faculty of Business, Economics \& Law, University of Queensland, Cnr Blair Drive \& Campbell Street, St Lucia, Queensland 4072, Australia.

Email: a.tkaczynski@uq.edu.au
} 
Muloin, 1998). For example, it was recently estimated that whale watching contributes US\$2.1 billion per annum of tourism revenue worldwide, employing approximately 13,000 people (O'Connor et al., 2009). Interestingly, seeing whales and enjoying wildlife trips are consistently ranked as an important influence on tourists enjoyment within some tourist destinations (Lopez and Pearson, 2017; Orams, 2000), and viewing these whales in proximity frequently influences a highly ranked experience and a satisfied tourist (Lopez and Pearson, 2017; Orams, 2000; Valentine et al., 2004).

In addition to recreation, whale watching provides an opportunity for wildlife conservation awareness and education for tourists (Zeppel, 2008; Zeppel and Muloin, 2008). However, tourists may exhibit different levels of interest in whale watching and conserving the environment (Duffus and Dearden, 1990; Malcolm and Duffus, 2008). These differences may be based on their personal characteristics such as their education, income, past experience or their interest in this wildlife activity, and conserving the environment in general. Some views consider that tourism marketing is exploitative and that tourism fuels hedonistic consumerism (Font and McCabe, 2017). Alternate views exist acknowledging that some forms of tourism (e.g. whale watching) are ecologically or sustainability focused (Hunter and Shaw, 2007; Ko, 2005). For some destinations, preservation of the natural environment is desirable while delivering economic benefit to the local community (Beaumont, 2001; Wilson and Tisdell, 2003). Therefore, approaches that can assist to identify high-income tourists who are interested in whale watching and conserving the environment and marine species are required. Such tactics may deliver tourists who are more willing to care for and hence conserve the environment they are visiting while delivering financial returns in the local economy.

While significant research has profiled tourists focusing on their environmental motivations (Dolnicar et al., 2008; Pan and Ryan, 2007), environmental values (Esparon et al., 2015; Winter, 2007), and environmentally focused behaviors (Andereck, 2009; Juvan and Dolnicar, 2014), few have sought to simultaneously assess environmental predispositions and economic potential. Furthermore, although past research has focused on profiling tourists, inadequate attention has been directed toward understanding whether market segments are enduring and stable
(Ernst and Dolnicar, 2018) and hence can be used by destination marketing organizations (DMOs) for effective tourism planning and development purposes.

These gaps in the literature provide the impetus for this research. Specifically, the aim of this study is to identify whether an environmentally focused and profitable whale-watching segment can be identified for subsequent targeting. Targeting will be assessed using Kotler's (1988) original target marketing criteria of measurability, substantiality, accessibility, and actionability. A fifth criterion is proposed, namely sustainability. The aim of this research is to first employ a selective segmenting approach to identify a segment (Bryan, 1977; Lambert et al., 2010) from a potentially heterogeneous whale-watching tourist market. This segment will be strategically aligned to a DMO seeking to maximize financial performance and visitation while maintaining the environment it depends on. Based on the five key target market criteria (Kotler, 1988), a segment can then be focused upon. Armed with this knowledge, tourism stakeholders can use marketing tools and techniques to attract and retain tourists who are interested in preserving the natural environment while simultaneously delivering economic benefit in the destination community. This article contributes to the literature proposing an extension to Kotler's (1988) targeting criteria, adding a fifth criteria termed 'sustainability'.

\section{Literature review}

\section{Wildlife tourism and conserving the natural environment}

Since the 1980s, there has been a growing concern for the well-being of the environment (Reynolds and Braithwaite, 2001). Parsons and Brown (2017) recently reviewed whale-watching research from 2005 onwards noting the impact of whale watching on cetaceans, compliance of whale-watching operators on legislative guidelines, and human dimensions of whalewatching management. It is consistently argued that the tension between satisfying the tourist while simultaneously protecting wildlife is an issue that tourism stakeholders face when designing whale-watching tours (Muloin, 1998; Ryan et al., 2018).

Largely due to wildlife tourism activities (e.g. whale watching) being increasingly based on environmentally friendly guidelines promoting 
conservation values, research has focused on identifying differences in tourist responses to environmental conservation messages (Wilson and Tisdell, 2003). For example, numerous tourism studies (e.g. Winter, 2007; Zografos and Allcroft, 2007) have incorporated methods such as the New Environmental Paradigm (Dunlap et al., 2000) to differentiate tourists grounded on their values and behavior toward the environment. Ajzen's (1991) theory of planned behavior has also been frequently employed (e.g. Lee and Moscardo, 2005; Stanford, 2014) to measure tourists' normative and subjective beliefs toward the environment and their resultant behavior.

Despite strategies such as conservation or education being designed by tourism stakeholders, tourists may vary considerably in their interest in conserving the tourism environment (Wilson and Tisdell, 2003). Identifying tourists who exhibit qualities associated with behaviors that are supportive of the environment offers one means to conserve precious wildlife resources over time. Font and McCabe (2017) concluded that considerable research has identified market segments that have pro-sustainable characteristics. This market development approach has produced a wave of new research across different tourism contexts with varying degrees of success (Babakhani et al., 2017; Cvelbar et al., 2017).

Increasing research is being employed to understand the paradox between what consumers' state as their preferences, attitudes and intentions, and their actual behavior (Font and McCabe, 2017). Schultz (2001) concluded that certain tourists will be motivated to participate in activities for self-orientated reasons such as maximizing their own experience with little or no regard for others or the environment. Studies have also aimed to prioritize tourists based on their level of engagement with an activity (Mehmetoglu, 2007; Zografos and Allcroft, 2007). In seeking to target-specific environmental segments, Blamey and Braithwaite (1997) focused upon four age-orientated segments that were defined as members of society that are interested in spending some of their vacation in the next year increasing their understanding and appreciation of nature. Dolnicar (2010) was also able to provide empirical evidence for a segment of individuals who engage strongly in environmentally friendly behavior to be prioritized when surveying Australian residents on their environmental practices while on vacation.

Several pioneering studies have been conducted to differentiate wildlife tourists based on their interest in a wildlife tourism activity and/or their attitude to the environment. Duffus and Dearden (1990) conceptualized wildlife tourists as either specialist or generalist according to their infrastructure needs and knowledge of the wildlife within its habitat. The authors, in employing first Butler's (1980) tourism area life cycle, second Bryan's (1977) specialist framework, and third the limits of acceptance change model, argued that as a site grows in popularity and visitor numbers, generalist wildlife tourists will grow to potentially exceed the specialist segments. Conversely, the numbers of wildlife specialists, who were the key initial drivers of the wildlife experience, will remain the same. Parsons et al. (2003b) identified three descriptive groups of tourists. The first group, hard-core enthusiasts, had a major motivation to see whales. The remaining two segments were interested in whale watching, albeit to a lesser extent.

Malcolm and Duffus (2008) employed a similar model to Duffus and Dearden (1990) while including personal characteristics of tourists. The authors argued that certain tourists might have a level of specialization for wildlife activity based on their prior experience, higher level of education, and interest in a leisure activity. The authors identified novice, intermediate, and advanced tourists. Advanced whale watchers who were more specialized (experienced) had strong environmental awareness and had more realistic expectations of the likelihood of not encountering whales. The authors concluded that if whale watching is to be a vehicle for conservation education, the novice whale watchers should be concentrated upon, as advanced tourists are more likely to be knowledgeable about whale watching and the need to be environmentally responsible. Malcolm and Duffus (2008) determined that the development of basic environmental education can also identify specific learning desires of novice tourists.

Lambert et al. (2010) adapted Duffus and Dearden's (1990) model of whale watching. These authors concluded that a specialist is dedicated to a whale-watching trip with the primary aim to see cetaceans. Generalists, conversely, aim to predominantly search for non-cetacean wildlife, although seeing cetaceans is relevant (2010). As the likelihood of observing a cetacean falls, the number of both tourism segments decreases. Catlin and Jones (2010) also employed Duffus and Dearden's (1990) earlier work for whale shark tourism. The authors suggested that while specialist tourists (segments) 
exist who are more concentrated on the focal species (whale sharks) and being environmentally conservative, generalists are the growing segment. Generalists have a greater interest in the non-wildlife aspects of the tourism experience such as the scenery, staff service, and food and beverages. The authors also determined that there was a greater age distribution of whale shark tourists (both young and old), with the total population having a higher tolerance to crowding of other tourists experiencing shark whale tourism.

\section{Whale watching target marketing}

Numerous studies have aimed to classify tourists into groups based on key environmental criterion (e.g. Babakhani et al., 2017; Cvelbar et al., 2017) and their level of interest in the wildlife activity (Duffus and Dearden, 1990; Malcolm and Duffus, 2008). Further, prior research indicates that whale watchers are likely to be aged over 30 (Muloin, 1996; Warburton et al., 2001), female (Lopez and Pearson, 2017; Sitar et al., 2017), travel with another person (Parsons et al., 2003a; Warburton et al., 2001), have a high level of education (Pearce and Wilson, 1995; Tilt, 1987), and a high social class/income (Pearce and Wilson, 1995; Warburton et al., 2001). These tourists are more likely to be domestic and on their first whale-watching experience with the provider (Malcolm and Duffus, 2008; Parsons et al., 2003a).

Despite this considerable research, it can be argued that the utility of employing theory in tourism segmentation research is still in its infancy, with data-driven research the focus of segmentation studies (Tkaczynski et al., 2018). Furthermore, although segments have been defined, consideration of the target marketing and positioning implications of derived segments have largely been ignored in segmentation research despite knowing that segments need to be measurable, substantial, accessible, and actionable (Kotler, 1988) to warrant further consideration (Tkaczynski et al., 2018). Briefly, measurability is the degree to which the size and purchasing power of all segments can be assessed. A market segment's substantiality depends on the size and the purchase volume of the specific segments (Spotts and Mahoney, 1991), with the target segment needing to be large enough to justify special attention (Mills et al., 1986) to ensure return on investment can be derived. Accessibility refers to the likelihood that a targeted segment can be serviced effectively through appropriate media strategies (Perdue, 1996), whereas the degree to which effective programs can be formulated for attractive and serving targeted segments represents actionability (Kotler et al., 2010).

Target marketing enables competitive strategies to be formulated (Ahmed et al., 1997) and specific markets can then be focused on based on their profitability (e.g. Jang et al., 2004; Perdue, 1996) or likelihood of conserving the environment (e.g. Dolnicar, 2010; Zografos and Allcroft, 2007). Segments can be targeted based on their likelihood of visiting a destination over a sustained period of time (Jang et al., 2004; Perdue, 1996) and their potential accessibility and responsiveness to promotional material. Conversely, failing to consider targeting segments based on key criteria limits marketing potential as resources can be wasted targeting differences that are not managerially practical nor meaningful (Tkaczynski et al., 2018).

\section{Conceptual framework}

The aim of this article is to examine whether the incorporation of a fifth factor (sustainability) in segmentation can better capture heterogeneity in the tourism market. While tourist attributes associated with environmental concern have received considerable attention (Dolnicar, 2010; Zografos and Allcroft, 2007) and segmentation of whalewatching tourists is evident (Malcolm and Duffus, 2008; Warburton et al., 2001), a more balanced targeted DMO view has yet to be considered. Due to a continual emphasis on environmental sustainability for wildlife tourism experiences, including interest in whale watching and the environment should represent a key segmentation criterion. If implemented, this process could benefit destinations enhancing sustainability in the longer term. This research aims to identify whether the number of segments derived varies when sustainability items are incorporated into segmentation analysis. The first research hypothesis follows:

H1: The number of segments will increase when sustainability factors are incorporated in segmentation analysis.

A second hypothesis is proposed that aims to identify whether Kotler's (1988) target marketing criteria can be employed where targeting one or a small number of segments that are profitable 
and environmentally focused is warranted. From a DMO viewpoint, first the identification of the segment that is sufficiently large enough to target profitably (substantial) can be differentiated (measurable) based on being the most likely to spend the most money while simultaneously exhibiting environmental concern to ensure sustainability over time (sustainable). This can be the key to enhancing destination performance in the longer term. These profitable and environmentally focused whale-watching tourists can be targeted through appropriate mediums (accessible) and will respond to environmental messages (actionable).

H2: There are significant differences in tourists characteristics based on Kotler's (1988) target market criterion to justify targeting one or a small number of segments.

\section{Hervey Bay whale watching}

Hervey Bay, located approximately $300 \mathrm{~km}$ north of Brisbane, the capital of Queensland in Australia, is a major Australian whale-watching destination (Tourism Australia, 2016) and is the focus of this study. Unofficially known as the whale watching capital of Australia, tourists have the opportunity to witness humpback whales and other cetacean marine life such as dolphins (Tourism and Events Queensland, 2014; Tourism Australia, 2016) at this coastal destination.

Hervey Bay is marketed as part of the Fraser Coast region, which also includes the rural city of Maryborough and the World Heritage listed Fraser Island. In 2013-2014, the tourism industry contributed approximately AUS $\$ 690$ million to the Fraser Coast regional economy ( $20 \%$ of gross regional product) and employment $(8.1 \%)$ of 2900 people (Tourism and Events Queensland, 2016c). The Fraser Coast is positioned as where nature comes alive and the target market is defined as connectors who live within a 400$\mathrm{km}$ drive market radius of the Fraser Coast and travel to the destination to bond with family and friends (Tourism and Events Queensland, 2016a). Whale watching is extensively promoted (e.g. television, billboards, and social media) by the Fraser Coast DMO to the key source markets. Hervey Bay's international whale-watching market has also grown substantially with 135,000 international visitors to Hervey Bay participating in whale watching in 2015 (Tourism and Events Queensland, 2016b).
A Hervey Bay whale-watching tour ranges in duration from half a day (e.g. $4 \mathrm{~h}$ ) to a full day (e.g. 8 h). To experience whales in their natural habitat (i.e. migrating from the Great Barrier Reef to Antarctica), whale watchers need to travel approximately $45 \mathrm{~min}$ from the Hervey Bay shore to the Sandy Strait within the Pacific Ocean in one of the seven licensed whalewatching vessels. Intimate tours that cater for a small number of tourists ( 24 or fewer and priced at approximately AUS\$150) are available. Alternatively, larger tours are provided for approximately 50-100 customers and are priced at roughly AUS $\$ 100$. All tours provide food, beverages, and a tour guide. Educational information on whales such as the different cetacean species and their migration patterns are available on all whale-watching vessels. Furthermore, certain operators provided tourists with documentation (e.g. compact disc or a brochure) on the importance of conserving the environment.

\section{Methodology}

A questionnaire was developed based first from personal interviews with whale-watching providers and the regional DMO managers and second from a review of the literature (e.g. Lambert et al., 2010; Lee and Moscardo, 2005; Malcolm and Duffus, 2008). In total, eight questions were employed in this study. In line with previous literature (e.g. Cheng and Wu, 2015; Powell and Ham, 2008), two psychographic measures relating to first whale watching and second the environment were designed using Likert scales $(1=$ lowest and $7=$ highest $)$. This process was utilized to measure the extent to which respondents varied in their interest in whale watching and conserving the natural environment.

Past experience was designed as a binary variable (yes/no) to indicate whether tourists were first or repeat Hervey Bay whale-watching tourists (e.g. Dolnicar, 2004; Yoo et al., 2004). The four demographic items of travel party composition (TPC), education, age, and income were all designed as categorical to permit comparisons with previous whale-watching research (e.g. Malcolm and Duffus, 2008; Pearce and Wilson, 1995). Drawing from the past tourism literature (Onyx and Leonard, 2005; Park et al., 2002), the geographic item, origin, was open-ended. This question was recoded into categories, which included Queensland $(<400 \mathrm{~km})$, Queensland $(>400 \mathrm{~km})$, Other Australia, Europe, New Zealand, and Other International. 
The sample population were tourists who participated in a guided commercial whalewatching experience in Hervey Bay. Respondents needed to be older than 18 years. A convenience sampling method was employed where on specific predetermined days, tourists who had participated in a whale-watching tour were asked to complete a self-administered questionnaire while on the return leg back to the Hervey Bay shore. Prior to exiting the whalewatching vessel, tourists submitted the questionnaire to the data collector. To maximize variation in responses and to cater for the high and shoulder seasons, data were collected across four periods from July to October 2015 and on multiple whale-watching vessels that varied in tourist capacities. All 7 days of the week were sampled to ensure that weekend domestic tourists who represent a large domestic cohort (Tourism and Events Queensland, 2016b) did not bias the solution.

Data collected in the survey were analyzed using the Predictive Analytics SoftWare (PASW), version 24.0. TwoStep cluster analysis method. The log-likelihood measure was utilized to reveal natural groupings in the data set. TwoStep cluster analysis simultaneously analyzes categorical and continuous data without data transformation and researcher bias (Norusis, 2011). TwoStep cluster analysis is appropriate for simultaneously assessing binary scale, Likert scale, and categorical data as applied within this research (Tkaczynski et al., 2015).

Best practice guidelines state that the sample size needs to be 100 times the number of segmentation variables (Dolnicar et al., 2016), which in this case meant a minimum sample size of 800 was required to cluster respondents based on the eight questions employed for this research. Second, the silhouette measure of cohesion and separation needs to be at or above 0.0 to ensure that the within-cluster distance and the between-cluster distance is valid (Norusis, 2011). Third, $\chi^{2}$ and $t$-tests were performed on the categorical and the continuous variables, respectively, to indicate which individual variables exhibited significant differences between segments. Fourth, the input (predictor) importance is measured to determine the importance of variables in a segment. A variable with a rating between 0.8 and 1.0 is highly important to cluster formation, whereas variables that are rated between 0.01 and 0.2 are less important (Norusis, 2011). Fifth, to ensure validity, crossvalidation is employed where the sample is split in half (Hair et al., 2006) to determine whether the same cluster formation is evident. Specifically, every odd numbered and even numbered tourist response was classed as the first half and second half solutions, respectively, in PASW. Comparisons between the final model and the two half solutions were conducted to validate the cluster analysis.

\section{Results}

A total of 1024 completed surveys were collected and entered into PASW. To provide an accurate representation of whale-watching tourists to Hervey Bay, responses that were from locals (Hervey Bay residents) or contained incomplete sections were removed. Consequently, the final total was 727 completed surveys. Respondents were highly interested in whale watching (sample mean $(\bar{x})=6.21$, standard deviation (SD) $=$ $1.013)$ and conserving nature $(\bar{x}=6.30, \mathrm{SD}=$ 0.950 ). Bivariate analysis indicated that interest in whale watching and conserving nature $(r=$ 0.381 ) was weakly associated, which is ideal for segmentation (Dolnicar and Grün, 2017). The majority of respondents had completed a bachelor's degree $(30.1 \%)$ and the two popular TPC categories were partner/spouse (37.1\%) and family (29.6\%). Most (82.1\%) had not previously been on a Hervey Bay whale-watching experience. Almost one-third (32.0\%) reported a family income in excess of AUS\$100,000 per year. Respondent age varied considerably, with 25-34 $(21.7 \%),<25(17.7 \%)$, and $45-54(17.7 \%)$ the most frequently identified categories. Respondents traveled from eight main locations, with Europe (31.2\%), and Queensland $(<400 \mathrm{~km}$; $29.4 \%$ ) the dominant source markets.

Seven variables were included in the segmentation model (see Tables 1 and 2) ensuring the model was valid. Three segments were produced, and all five validation criteria were achieved. First, 103.9 cases per variable produced market segment recovery (Dolnicar et al., 2016). Second, the Bayesian information criterion measure was fair $(0.1>0.0)$, indicating the model warranted further analysis. Third, $t$-tests and $\chi^{2}$ tests confirmed that all seven items were statistically significant $(p<0.05)$. Fourth, in measuring the input (predictor) importance to identify the importance levels of a variable in a cluster solution, all seven items produced cluster importance. Age (1.00) provided the highest level of differentiation among segments, whereas interest in conserving nature $(0.01)$ had the least 
Table I. Cluster input (predictor importance).

\begin{tabular}{|c|c|c|c|}
\hline & Combined solution & First half & Second half \\
\hline \multirow[t]{2}{*}{$0.8-1.0$} & Age (1.00) & Origin (1.00) & Age $(1.00)$ \\
\hline & & Age $(0.87)$ & \\
\hline $0.4-0.8$ & & TPC $(0.50)$ & $\mathrm{TPC}(0.42)$ \\
\hline \multirow[t]{3}{*}{$0.2-0.4$} & Origin $(0.34)$ & Education (0.37) & Origin $(0.33)$ \\
\hline & $\operatorname{TPC}(0.33)$ & Past experience $(0.24)$ & Education (0.27) \\
\hline & Income $(0.27)$ & Income $(0.23)$ & Income $(0.23)$ \\
\hline \multirow[t]{3}{*}{$0.01-0.2$} & Education (0.18) & $\begin{array}{l}\text { Conserving nature interest } \\
(0.03)\end{array}$ & Past experience $(0.09)$ \\
\hline & Past experience $(0.08)$ & & $\begin{array}{l}\text { Conserving nature interest } \\
(0.01)\end{array}$ \\
\hline & $\begin{array}{l}\text { Conserving nature interest } \\
(0.01)\end{array}$ & & \\
\hline $\begin{array}{l}\text { Average silhouette } \\
\text { measure }\end{array}$ & 0.1 & 0.1 & 0.1 \\
\hline
\end{tabular}

TPC: travel party composition.

importance in cluster formation. Finally, when splitting the file into two, it was concluded that three segments were again identified with minimum differences between the final and the first and second half solutions (see Table 1). As noted in the cluster solutions, age is consistently identified as the most important discriminator, whereas an interest in conserving nature was consistently the least important variable in distinguishing the four segments in all three solutions. As all five validity solutions were upheld, the cluster solution was retained (see Table 2 for an overview of the solution) and both hypotheses were supported.

The first segment, labeled young inexperienced Europeans, is the smallest (14.6\%) and is differentiated based on this segments younger age $(<25 ; 89.6 \%)$, lack of whale-watching experience $(2.8 \%)$, and low income ( $<$ AUS $\$ 20,000$; $55.7 \%)$. These tourists are also the least interested in conserving nature $(\bar{x}=6.02)$ and travel predominantly with family $(49.1 \%)$ and friends (30.2\%). The second segment, educated but inexperienced European couples, represents approximately a fifth $(20.4 \%)$ of the sample. Tourists in the second segment are distinguished based on their European origin ( $85.1 \%$ ), almost nonexistent past whale-watching experience $(0.7 \%)$, young age (25-34; 70.3\%), high education levels (74.4\% - at least bachelor level), and traveling with a partner/spouse $(61.5 \%)$.

The third segment, older-aged domestics, represents almost $(30.1 \%)$ of the sample. These tourists are distinguished based on their domestic origin $(92.8 \%)$, middle age $(71.2 \%$; over 55$)$, high past experience (33.8\%), and highest interest in conserving nature $(\bar{x}=6.41)$. The fourth segment is the largest (34.9\%). This segment's label as wealthy domestic families reflects the segments middle age (35-54), high income (54.7\%; AUS $\$ 100,000+)$, and their tendency to travel with family (57.9\%). Over three-quarters (78.0\%) travel from within Australia (e.g. Queensland, New South Wales, and Victoria) and approximately a half of this segment are tertiary educated (54.3\%). The final segment also has a high interest in conserving nature $(\bar{x}=$ $6.35)$ and a small percentage $(20.5 \%)$ have previous whale-watching experience.

\section{Targeting a profitable and environmentally focused segment}

Four valid segments that were differentiated based on seven variables were identified within this study. This, therefore, fulfills Kotler's (1988) most commonly met assumption of measurability for segmentation in tourism research. The wealthy domestic families segment (the fourth segment) should be the target market for Hervey Bay whale-watching operators due to most effectively fulfilling Kotler's (1988) three remaining target marketing criteria and a fifth criteria (sustainability).

In considering first substantiality, this segment is the largest (34.9\%) and contains the highest percentage (over 55\%) of tourists with a high income. This segment, therefore, is large and profitable enough to warrant special attention (Mills et al., 1986). Previous academic (Tkaczynski et al., 2010) and industry (Tourism Queensland, 2007) research has also determined 
Table 2. Cluster solution.

\begin{tabular}{|c|c|c|c|c|}
\hline & $\begin{array}{l}\text { Young inexperience } \\
\text { Europeans (14.6\%) }\end{array}$ & $\begin{array}{c}\text { Educated but } \\
\text { inexperienced } \\
\text { European } \\
\text { couples }(20.4 \%)\end{array}$ & $\begin{array}{c}\text { Older aged } \\
\text { domestics } \\
(30.1 \%)\end{array}$ & $\begin{array}{c}\text { Wealthy } \\
\text { domestic } \\
\text { families }(34.9 \%)\end{array}$ \\
\hline Categorical variable & $\%$ & $\%$ & $\%$ & $\%$ \\
\hline \multicolumn{5}{|l|}{ Age (years) } \\
\hline$<25$ & 89.6 & 14.9 & 2.2 & 2.8 \\
\hline $25-34$ & 1.9 & 70.3 & 14.6 & 7.9 \\
\hline $35-44$ & 1.9 & 4.7 & 0.9 & 41.7 \\
\hline $45-54$ & 5.7 & 2.7 & 11.0 & 37.4 \\
\hline $55-64$ & 0.9 & 5.4 & 42.0 & 5.9 \\
\hline $65+$ & 0.0 & 2.0 & 29.2 & 4.3 \\
\hline \multicolumn{5}{|l|}{ Origin } \\
\hline Queensland (<400 km) & 13.2 & 4.1 & 41.6 & 40.6 \\
\hline Queensland (>400 km) & 7.5 & 2.0 & 4.6 & 5.1 \\
\hline New South Wales & 6.6 & 0.0 & 21.9 & 15.4 \\
\hline Victoria & 9.4 & 2.0 & 13.2 & 11.0 \\
\hline Other Australia states & 1.9 & 0.0 & 11.0 & 5.9 \\
\hline Europe & 59.4 & 85.1 & $\mathrm{I} .4$ & 13.8 \\
\hline New Zealand & 1.9 & 0.0 & 5.5 & 3.1 \\
\hline Other international & 0.0 & 6.8 & 0.9 & 5.1 \\
\hline \multicolumn{5}{|l|}{ TPC } \\
\hline Myself & 7.5 & 8.1 & 7.8 & 1.6 \\
\hline Partner/spouse & 0.9 & 61.5 & 58.9 & 19.3 \\
\hline Family & 49.1 & 3.4 & 5.0 & 57.9 \\
\hline Friends & 30.2 & 15.5 & 12.3 & 1.2 \\
\hline Other & 0.0 & 2.7 & 0.0 & 2.4 \\
\hline Partner + Family & 3.8 & 0.7 & 4.6 & 10.6 \\
\hline Family + Friends & 4.7 & 0.7 & 0.0 & 5.5 \\
\hline Partner + Family + Friends & 2.8 & 0.7 & 2.3 & 1.6 \\
\hline Partner + Friends & 0.9 & 6.8 & 9.1 & 0.0 \\
\hline \multicolumn{5}{|l|}{ Income } \\
\hline$<$ AUS $\$ 20,000$ & 55.7 & 8.8 & 9.1 & 0.4 \\
\hline AUS $\$ 20,000-A \cup S \$ 39,999$ & 2.8 & 18.2 & 15.5 & 4.7 \\
\hline AUS $\$ 40,000-A U S \$ 59,999$ & 5.7 & 23.6 & 16.4 & 9.1 \\
\hline AUS $\$ 60,000-A \cup S \$ 79,999$ & 3.8 & 18.9 & 16.0 & 16.1 \\
\hline AUS $\$ 80,000-A \cup S \$ 99,999$ & 2.8 & 11.5 & 16.4 & 13.4 \\
\hline AUS $\$ 100,000+$ & 20.8 & 15.5 & 22.4 & 54.7 \\
\hline Unsure & 8.5 & 3.4 & 4.1 & 1.6 \\
\hline \multicolumn{5}{|l|}{ Education } \\
\hline Primary & 16.0 & 0.0 & 0.9 & 1.2 \\
\hline Secondary & 42.5 & 6.1 & 40.2 & 12.2 \\
\hline Trade/TAFE & 14.2 & 19.6 & 26.5 & 32.3 \\
\hline Bachelor & 21.7 & 42.6 & 26.0 & 29.9 \\
\hline Postgraduate & 5.7 & 31.8 & 6.4 & 24.4 \\
\hline \multicolumn{5}{|l|}{ Binary variable } \\
\hline \multicolumn{5}{|l|}{ Past experience } \\
\hline Yes & 2.8 & 0.7 & 33.8 & 20.5 \\
\hline \multicolumn{5}{|l|}{ Continuous variable } \\
\hline Interested in conserving nature & $\begin{array}{l}\text { 6.02- } \bar{x}, \\
1.35-S D\end{array}$ & $\begin{array}{c}6.25-\bar{x} \\
0.95-S D\end{array}$ & $\begin{array}{c}6.41-\bar{x} \\
0.86-S D\end{array}$ & $\begin{array}{c}6.35-\bar{x} \\
0.95-S D\end{array}$ \\
\hline
\end{tabular}

$\bar{x}$ : sample mean; SD: standard deviation; TPC: travel party composition; TAFE: Technical and Further Education.

a similarly identified target market to the Fraser Coast region (wealthy travelers) over the past decade, suggesting this segment has and will continue to whale watch in Hervey Bay. The third segment, older-aged domestics, is the second largest and also has the greater level of experience with whale watching. However, due to their lower income and potentially being retired or close to retirement (a high percentage $65+$ ), their potential profitability over time may 
be more limited when compared to the fourth segment. Furthermore, this segment shows similarities to a less profitable segment, long-stay travelers, previously identified in academic research at the Fraser Coast (Tkaczynski et al., 2010) who travel domestically with their partner from Eastern Australia and spend little money on food, accommodation, and activities while on holiday.

In considering Perdue's (1996) finding that geographic proximal markets are the most accessible (accessibility), in combination with the previous target marketing selection criteria (substantiability), the wealthy domestic families should be prioritized. In addition to their high income, this segment is geographically close by Australian standards $(<400 \mathrm{~km} ; 40.6 \%$ of the segment), representing connectors that are currently targeted by the regional DMO (Tourism and Events Queensland, 2014). Specifically, these tourists earn over AUS\$100,000+ per annum and are from domestic source markets of Queensland (45.7\%), New South Wales $(15.4 \%)$, and Victoria (11.0\%) and they are currently actively targeted by the regional and state DMO (Tourism and Events Queensland, 2014). Through continuing to focus upon this segment in current marketing and promotional campaigns such as billboards and social media, this segment can be served effectively (Kotler, 1988), therefore fulfilling the third target marketing criterion.

Actionability represents the most positive yet challenging target market criterion. Marketers have a responsibility to design products that are environmentally sustainable (Font and McCabe, 2017) yet attractive to target segments. Although the high percentage of whale watching tourists across the four segments are interested in whale watching and also conserving the natural environment, the degree to which effective programs can be formulated for attracting and serving the wealthy domestic family segment (Kotler et al., 2010) differently from the other three segments may be difficult. Hervey Bay is actively promoted as a whale-watching destination that has attracted tourists to the region from close and distant regions to experience this nature-based activity for several decades (Tourism and Events Queensland, 2015). Although it is recommended to continue to promote the importance of conservation and the wonder of a whale-watching experience, the wealthy domestic families segment presents the greatest return of financial and environmental dividends opportunity for the tourism stakeholders.
Sustainability was proposed as a fifth criterion to extend Kotler's (1988) four targeting criteria. Preserving the very natural environment that attracts tourist visitation is a key managerial concern for destinations. Dual consideration of a destinations economic imperative that generates employment and contributes to local wealth for an economy in tandem with environmental concern ensures that DMOs are able to attract tourists that deliver short-term benefits (economic contribution) and long-term outcomes (preserving the natural environment), ensuring destinations can thrive in the longer term. The fourth segment offered the greatest economic capacity (high income) while simultaneously expressing a high interest in conserving nature. This segment, therefore, offers both economic benefits for the destination while expressing attitudes that are consistent with actions that would benefit the local environment. Based on the sustainability criterion, this segment should be the primary focus for DMO marketing.

\section{Discussion and conclusion}

Whale watching is a growing form of wildlife tourism form that represents and provides a variety of benefits to tourism stakeholders if strategically designed (Lopez and Pearson, 2017; Ryan et al., 2018). As this article proposes, inadequate attention has been directed toward understanding whether environmentally focused market segments are enduring. This provided the impetus for this study. Through employing a conceptual framework with two research hypotheses, an environmentally focused and profitably whale-watching segment (wealthy domestic families) was identified and targeted. Several contributes have been made, which are now discussed in turn.

The major theoretical contribution of this research is that it has proposed and applied a fifth targeting criterion that can be employed by destination marketers extending Kotler's (1988) original target criterion. Inclusion of the sustainability criterion in conjunction with the original four criteria proposed by Kotler (1988) ensures that the DMOs can attract tourists who deliver high return on investment for the destination while simultaneously conserving the environment. Although a plethora of research has been employed to profile environmentally focused tourists into segments (Blamey and Braithwaite, 1997; Dolnicar, 2010), research had overlooked the economic value that could potentially be 
derived from segments targeted that have an interest in conserving the natural environment.

Wildlife tourism activities such as whale watching based on environmentally friendly guidelines can potentially promote conservation values and further educate tourists (Lopez and Pearson, 2017; Wilson and Tisdell, 2003). Consequently, future research seeking to define a profitable and environmental segment needs to follow a similar procedure outlined in this research. While segments may be different and can be validated (e.g. measurable), which is largely considered the easiest target market criterion (Tkaczynski et al., 2018), if they are not sustainable in the long term from both an environmental and a financial point of view, they do not warrant marketing attention. Furthermore, DMOs need to ensure that the targeted segment can continually be accessed through appropriate media (e.g. brochures and social media) and likely to respond to associated marketing messages through continual market research (Kotler et al., 2010; Perdue, 1996).

This study confirms the tourism literature (e.g. Tkaczynski et al., 2010; Tkaczynski et al., 2015) that the four segmentation bases of demographic (age, income, education, and TPC), geographic (origin), psychographics (interest in conserving nature), and behavioral (past experience) first proposed by Kotler (1980) can be successfully employed to profile whale-watching tourists. Whale-watching tourists in this research are actively involved in experiencing marine life (Lambert et al., 2010; Orams, 2000), aged over 30 (Muloin, 1998; Warburton et al., 2001), and travel with another person (Parsons et al., 2003a; Sitar et al., 2017). These tourists also have a high level of education and social class (Pearce and Wilson, 1995; Sitar et al., 2017), travel domestically (Finkler and Higham, 2004; Hoyt, 2001), and on their first whale-watching experience (Lopez and Pearson, 2017; Malcolm and Duffus, 2008). Consequently, all four segmentation bases and the seven segmentation variables are required by academics and practitioners to provide a strategic basis for market segmentation.

A final contribution of this research is that it also identified the variables that produced greater variance among segments. Specifically, it determined that age, origin, and TPC were the major discriminators that can be used by academics and practitioners when seeking to profile and target future whale-watching segments. Consequently, external validation for this study could be confirmed (e.g. Wedel and Kamakura, 2000). While psychographic measures within the sustainability literature (e.g. Cheng and $\mathrm{Wu}, 2015$; Powell and Ham, 2008) employ Likert scales that formed the basis for this study, these variables (whalewatching interest, conserving nature interest) was minimal or nonexistent. Past tourism research has indicated that employing binary measures may deliver enhanced ability to differentiate segments (Dolnicar and Grün, 2013). Consequently, this study suggests that Likert scales may be inappropriate in segment solutions, and to improve the internal validation of segmentation solutions (Wedel and Kamakura, 2000), binary measures should be employed (Dolnicar and Grün, 2013).

\section{Limitations and opportunities for future research}

This research is not without its limitations. These restrictions present opportunities for future research. The first limitation of this research is that it was only conducted at one regional destination (Fraser Coast). An opportunity for future research is to conduct research in whale-watching destinations such as Kangaroo Island and Fremantle (Australia), Juneau and Tofino (North America), or Reykjavik and Tromsø (Scandinavia) in addition to the Fraser Coast to improve the generalizability of these research findings.

A major limitation is that despite measuring the levels of interest in whale watching and in protecting nature, the study did not aim to identify what environmental values tourists had or wished to experience during their whalewatching experience. Future research into wildlife segmentation could employ models such as the New Environmental Paradigm (Dunlap et al., 2000) to identify specific elements of the environment that tourists value. This could include the whale-watching experience itself or the opportunity for traveling on a marine boat.

Results from the current study indicate that the domestic wealthy families segment offers the most potential for tourist marketers. A study could be designed to test whether a decision to focus marketing expenditure on this one segment could improve return on investment. A $2 \times 3$ experimental design would permit testing of the current campaign against a campaign designed specifically to attract this segment to assess likelihood to travel in future in a cross-sectional design or actual travel behavior in a longitudinal study design. 
Finally, this study is limited to a whalewatching context, which represents opportunities for future research to extend understanding of application of the sustainability targeting criterion. Natural environment and wildlife tourism destinations are many and varied. Future research is recommended to extend the method applied in the current study to understand whether sustainable segments can be identified for various wildlife tourism experiences. Additionally, research is recommended to understand whether the sustainability criterion can be applied to nature-based tourism destinations.

\section{Declaration of conflicting interests}

The author(s) declared no potential conflicts of interest with respect to the research, authorship, and/or publication of this article.

\section{Funding}

The author(s) received no financial support for the research, authorship, and/or publication of this article.

\section{ORCID iD}

Aaron Tkaczynski (D) https://orcid.org/00000002-3410-7602

\section{References}

Ahmed SA, Barber M, and D'astous A (1997) Segmentation of the Nordic winter sun seekers market. Journal of Travel \& Tourism Marketing 7: 39-63.

Ajzen I (1991) The theory of planned behavior. Organizational Behavior and Human Decision Processes 50: 179-211.

Andereck K (2009) Tourists' perceptions of environmentally responsible innovations at tourism businesses. Journal of Sustainable Tourism 17: 489-499.

Babakhani N, Ritchie BW, and Dolnicar S (2017) Improving carbon offsetting appeals in online airplane ticket purchasing: testing new messages, and using new test methods. Journal of Sustainable Tourism 25: 955-969.

Beaumont N (2001) Ecotourism and the conservation ethic: Recruiting the uninitiated or preaching to the converted?. Journal of Sustainable Tourism 9: 317-341.

Blamey RK and Braithwaite VA (1997) A social values segmentation of the potential ecotourism market. Journal of Sustainable Tourism 5: 29-45.

Bryan H (1977) Leisure value systems and recreational specialization: the case of trout fishermen. Journal of Leisure Research 9: 174-187.
Butler R (1980) The concept of a tourist area cycle of evolution: implications for management of resources. Canadian Geographer 24: 5-12.

Catlin J and Jones R (2010) Whale shark tourism at Ningaloo Marine Park: a longitudinal study of wildlife tourism. Tourism Management 31: 386-394.

Cheng T-M and Wu HC (2015) How do environmental knowledge, environmental sensitivity, and place attachment affect environmentally responsible behavior? An integrated approach for sustainable island tourism. Journal of Sustainable Tourism 23: 557-576.

Curtin S (2006) Swimming with dolphins: a phenomenological exploration of tourist recollections. International Journal of Tourism Research 8: 301-315.

Cvelbar LK, Grün B, and Dolnicar S (2017) Which hotel guest segments reuse towels? Selling sustainable tourism services through target marketing. Journal of Sustainable Tourism 25: 921-934.

Dolnicar S (2004) Insights into sustainable tourists in Austria: a data-based a priori segmentation approach. Journal of Sustainable Tourism 12: 209-218.

Dolnicar S (2010) Identifying tourists with smaller environmental footprints. Journal of Sustainable Tourism 18: 717-734.

Dolnicar S, Crouch GI, and Long P (2008) Environment-friendly tourists: What do we really know about them? Journal of Sustainable Tourism 16: 197-210.

Dolnicar S and Grün B (2013) Validly measuring destination image in survey studies. Journal of Travel Research 52: 3-14.

Dolnicar S and Grün B (2017) Methods of segmentation. In: Dietrich T and Rundle-Thiele SR (eds) Segmentation in Social Marketing. Singapore: Springer, pp. 93-107.

Dolnicar S, Grün B, and Leisch F (2016) Increasing sample size compensates for data problems in segmentation studies. Journal of Business Research 69: 992-999.

Duffus DA (1988) Non-consumptive Use and Management of Cetaceans in British Columbia Coastal Waters. Victoria: University of Victoria.

Duffus DA and Dearden P (1990) Non-consumptive wildlife-oriented recreation: a conceptual framework. Biological Conservation 53: 213-231.

Dunlap RE, VanLiere KD, Mertig AG, et al. (2000) Measuring endorsement of the new ecological paradigm: a revised NEP scale. Journal of Social Issues 56: 425-442.

Ernst D and Dolnicar S (2018) How to avoid random market segmentation solutions. Journal of Travel Research 57: 69-82. 
Esparon M, Stoeckl N, Farr M, et al. (2015) The significance of environmental values for destination competitiveness and sustainable tourism strategy making: insights from Australia's great barrier reef world heritage area. Journal of Sustainable Tourism 23: 706-725.

Finkler W and Higham J (2004) The human dimensions of whale watching: an analysis based on viewing platforms. The Human Dimensions of Wildlife 9: 103-117.

Font X and McCabe S (2017) Sustainability and marketing in tourism: its contexts, paradoxes, approaches, challenges and potential. Journal of Sustainable Tourism 25: 869-883.

Hair JFJ, Black WC, Babin BJ, et al. (2006) Multivariate Data Analysis. NJ: Pearson Education.

Hoyt E (2001) Whale Watching 2001: Worldwide Tourism Numbers, Expenditures and Expanding Socioeconomic Benefits. Crowborough: International Fund for Animal Welfare.

Hunter C and Shaw J (2007) The ecological footprint as a key indicator of sustainable tourism. Tourism Management 28: 46-57.

Jang S, Morrison AM, and O'Leary JT (2004) A procedure for target market selection in tourism. Journal of Travel \& Tourism Marketing 16: 19-33.

Juvan E and Dolnicar S (2014) Can tourists easily choose a low carbon footprint vacation? Journal of Sustainable Tourism 22: 175-194.

Ko TG (2005) Development of a tourism sustainability assessment procedure: a conceptual approach. Tourism Management 26: 431-445.

Kotler P (1980) Principles of Marketing. Englewood Cliffs: Prentice-Hall.

Kotler P (1988) Marketing Management: Analysis, Planning, Implementation, and Control. Englewood Cliffs: Prentice Hall.

Kotler P, Bowen JT, and Makens JC. (2010) Marketing for Hospitality and Tourism. Upper Saddle River: Pearson Prentice Hall.

Lambert E, Hunter C, Pierce GJ, et al. (2010) Sustainable whale-watching tourism and climate change: towards a framework of resilience. Journal of Sustainable Tourism 18: 409-427.

Lee WH and Moscardo G (2005) Understanding the impact of ecotourism resort experiences on tourists' environmental attitudes and behavioural intentions. Journal of Sustainable Tourism 13: 546-565.

Lopez G and Pearson HC (2017) Can whale watching be a conduit for spreading educational and conservation messages? A case study in Juneau, Alaska. Tourism in Marine Environments 12: 95-104.

Malcolm C and Duffus DA (2008) Specialization of whale watchers in British Columbia waters. In: Higham JES and Lück M (eds) Marine Wildlife and Tourism Management: Insights from the Natural and Social Sciences. Oxfordshire: CABI International, pp. 109-129.

Mehmetoglu M (2007) Nature-based tourists: the relationship between their trip expenditures and activities. Journal of Sustainable Tourism 15: 200-215.

Mills AS, Couturier H, and Snepenger DJ (1986) Segmenting Texas snow skiers. Journal of Travel Research 25: 19-23.

Muloin S (1996) Whale Watching in Hervey Bay: Results from Matilda II. In: Dept of Tourism. Townsville: James Cook University. Unpublished, p. 12.

Muloin S (1998) Wildlife tourism: the psychological benefits of whale watching. Pacific Tourism Review 2: 199-213.

Norusis M (2011) IBM SPSS Statistics 19 Procedures Companion. Boston: Addison Wesley.

O'Connor S, Campbell R, Cortez H, et al. (2009) Whale Watching Worldwide: Tourism Numbers, Expenditures and Expanding Economic Benefits: A Special Report. USA: International Fund for Animal Welfare.

Onyx J and Leonard R (2005) Australian grey nomads and American snowbirds: similarities and differences. The Journal of Tourism Studies 16: 61-68.

Orams MB (2000) Tourists getting close to whales, is it what whale-watching is all about? Tourism Management 21: 561-569.

Pan S and Ryan C (2007) Mountain areas and visitor usage-motivations and determinants of satisfaction: the case of Pirongia Forest Park, New Zealand. Journal of Sustainable Tourism 15: 288-308.

Park M, Yang X, Lee B, et al. (2002) Segmenting casino gamblers by involvement profiles: A Colorado example. Tourism Management 23: 55-65.

Parsons ECM and Brown DM (2017) Recent advances in whale-watching research: 2015-2016. Tourism in Marine Environments 12: 125-137.

Parsons ECM, Warburton CA, Woods-Ballard A, et al. (2003a) The value of conserving whales: the impacts of cetacean-related tourism on the economy of rural West Scotland. Aquatic conservation: marine and freshwater ecosystems 13: 397-415.

Parsons ECM, Warburton CA, Woods-Ballard A, et al. (2003b) Whale-watching tourists in West Scotland. Journal of Ecotourism 2: 93-113.

Pearce DG and Wilson PM (1995) Wildlife-viewing tourists in New Zealand. Journal of Travel Research 37: 19-26.

Perdue RR (1996) Target market selection and marketing strategy: the Colorado downhill skiing industry. Journal of Travel Research 34: 39-46.

Powell RB and Ham SH (2008) Can ecotourism interpretation really lead to pro-conservation 
knowledge, attitudes and behaviour? Evidence from the Galapagos Islands. Journal of Sustainable Tourism 16: 467-489.

Reynolds PC and Braithwaite D (2001) Towards a conceptual framework for wildlife tourism. Tourism Management 22: 31-42.

Ryan C, Bolin V, Shirra L, et al. (2018) The development and value of whale-watch tourism in the west of Scotland. Tourism in Marine Environments 13: 17-24.

Schultz PW (2001) The structure of environmental concern: concern for self, other people, and the biosphere. Journal of Environmental Psychology 21: 327-339.

Sitar A, May-Collado LJ, Wright A, et al. (2017) Tourists' perspectives on dolphin watching in Bocas Del Toro, Panama. Tourism in Marine Environments 12: 79-94.

Spotts DM and Mahoney EM (1991) Segmenting visitors to a destination region based on the volume of their expenditures. Journal of Travel Research 29: 24-31.

Stanford DJ (2014) Reducing visitor car use in a protected area: a market segmentation approach to achieving behaviour change. Journal of Sustainable Tourism 22: 666-683.

Tilt WC (1987) From whaling to whale watching. In: Transactions of the North American Wildlife and Natural Resources Conference 52: 567-585.

Tkaczynski A, Rundle-Thiele SR, and Beaumont N (2010) Destination segmentation: a recommended two-step approach. Journal of Travel Research 49: 139-152.

Tkaczynski A, Rundle-Thiele SR, and Prebensen NK (2015) Segmenting potential nature-based tourists based on temporal factors: the case of Norway. Journal of Travel Research 54: 251-265.

Tkaczynski A, Rundle-Thiele SR, and Prebensen NK (2018) To segment or not? That is the question. Journal of Vacation Marketing 24: 16-28.

Tourism and Events Queensland (2014) Fraser Coast Destination Tourism Plan. Brisbane: Tourism and Events Queensland.

Tourism and Events Queensland (2015) Hervey Bay Whale Watching. Available at: http://www.queens land.com/Explore-Queensland/Fraser-Coast/ Things-to-See-and-Do/Whales (accessed 14 November 2017).

Tourism and Events Queensland (2016a) Fraser Coast-Brand Story. Available at: http://teq. queensland.com/en-IN/Destinations/Fraser-Coast/ Brand-Story (accessed 14 November 2017).

Tourism and Events Queensland (2016b) International Visitors to Fraser Coast and Participated in a Whale or Dolphin Watching Activity on Their
Trip to Australia. Brisbane: Tourism and Events Queensland.

Tourism and Events Queensland (2016c) Regional Tourism Satellite Account Fraser Coast 2013-14. Available at: https://d2psoxjwp45svd.cloudfront. net/ /media/F9B33A1E237D4C1DB219CE3 BF8C9A67C.ashx?la $=$ en-IN\&vs $=1 \& d=000101$ $01 \mathrm{~T} 000000$.

Tourism Australia (2016) Whale Watching in Australia. Available at: http://www.australia.com/en/arti cles/nat-whalewatching.html (accessed 14 November 2017).

Tourism Queensland (2007) Fraser Coast Destination Management Plan. Available at: http://www.tq. com.au/shadomx/apps/fms/fmsdownload.cfm? file_uuid=D4461468-0810-C6E8-0005-2C8963 86472B\&siteName $=$ tqcorp_06 $($ accessed 14 November 2017).

Valentine PS, Birtles A, Curnock M, et al. (2004) Getting closer to whales-passenger expectations and experiences, and the management of swim with dwarf minke whale interactions in the Great Barrier Reef. Tourism Management 25: 647-655.

Warburton CA, Parsons ECMW-B, Hughes A, et al. (2001) Whale-watching in West Scotland. Available at: http://whaledolphintrust.co.uk/cust_images/ research\%20publications/Whalewatching_West Scotland.pdf (accessed 14 November 2017).

Wedel M and Kamakura WA (2000) Market Segmentation: Conceptual Methodological Foundations. New York: Springer.

Wilson C and Tisdell C (2003) Conservation and economic benefits of wildlife-based marine tourism: sea turtles and whales as case studies. Human Dimensions of Wildlife 8: 49-58.

Winter C (2007) The intrinsic, instrumental and spiritual values of natural area visitors and the general public: a comparative study. Journal of Sustainable Tourism 15: 599-614.

Yoo JJ-E, McKercher B, and Mena M (2004) Crosscultural comparison of trip characteristics: international visitors to Hong Kong from mainland China and USA. Journal of Travel \& Tourism Marketing 16: $65-77$.

Zeppel H (2008) Education and conservation benefits of marine wildlife tours: developing free-choice learning experiences. The Journal of Environmental Education 39: 3-18. DOI: 10.3200/JOEE.3239. 3203.3203-3218

Zeppel H and Muloin S (2008) Conservation benefits of interpretation on marine wildlife tours. Human Dimensions of Wildlife 13: 280-294.

Zografos C and Allcroft D (2007) The environmental values of potential ecotourists: a segmentation study. Journal of Sustainable Tourism 15: 44-66. 